\title{
Assessment of symptomatic response as predictor of Helicobacter pylori status following eradication therapy in patients with ulcer
}

\author{
K E L McColl, A El-Nujumi, L S Murray, E M El-Omar, A Dickson, A W Kelman, \\ T E Hilditch
}

\begin{abstract}
Background-Helicobacter pylori eradication therapy is routinely used for treating patients with peptic ulcer disease.

Aims-To assess the value of symptomatic response to $H$ pylori eradication therapy as a marker of post-treatment $H$ pylori status.
\end{abstract}

Patients and methods-One hundred and nine dyspeptic patients with active duodenal or gastric ulceration associated with $H$ pylori infection had their symptoms measured by a validated questionnaire before and three months following $H$ pylori eradication therapy. The symptomatic response was compared with posttreatment $H$ pylori status as determined by the ${ }^{14} \mathrm{C}$ urea breath test.

Results-An eradication rate of $84 \%$ was achieved. Of the 92 patients eradicated of $H$ pylori, $47 \%$ experienced complete or near complete resolution of dyspepsia. Of the 17 patients in whom the infection was not eradicated, only one $(6 \%)$ experienced resolution of dyspepsia. Resolution of dyspepsia was therefore a powerful predictor of eradication of $\boldsymbol{H}$ pylor $i$ with a predictive value of $98 \%$. In contrast, persistence of dyspepsia was a weak predictor of persisting infection with a predictive value of only $25 \%$. Excluding patients with endoscopic evidence of coexisting oesophagitis and/or retrosternal discomfort or reflux at initial presentation did not increase the predictive value of persisting dyspepsia for persisting infection.

Conclusions-Complete resolution of dyspeptic symptoms is a powerful predictor of eradication of $H$ pylori infection in ulcer patients. Persistence of symptoms is a weak predictor of persisting infection and patients with persisting dyspepsia must have their $H$ pylori status rechecked to guide future management.

(Gut 1998;42:618-622)

Keywords: Helicobacter pylori; dyspepsia; ulcer disease; eradication therapy; reflux disease

Eradication of Helicobacter pylori infection is now accepted as the first line treatment for patients with duodenal or gastric ulcers unassociated with non-steroidal anti-inflammatory drug therapy. Current anti-H pylori treatments achieve eradication rates of $60-95 \%$ and consequently a proportion of subjects will remain infected after such treatment and require a further course of an alternative anti- $H$ pylori regimen. At present it is unclear whether ulcer patients should be routinely tested to confirm eradication of $H$ pylori or whether symptomatic response is a reliable surrogate marker of post-treatment $H$ pylori status.

The aim of this prospective double blind study was to assess the value of dyspeptic symptoms as a marker of post-treatment $H$ pylori status in patients with ulcers.

\section{Patients}

The study involved 114 patients referred for endoscopic investigation of dyspepsia and who were found to have active duodenal and/or gastric ulceration associated with $H$ pylori infection. Patients were not included if they were taking non-steroidal anti-inflammatory drugs (excluding low dose aspirin). Dyspepsia was defined as pain, discomfort, or other symptoms believed to originate from the upper gastrointestinal tract.

\section{Methods}

At their initial interview and prior to the endoscopic examination, all patients had the severity of their dyspeptic symptoms over the preceding six month period assessed by means of an abbreviated version of the Glasgow Dyspepsia Severity Score. ${ }^{1}$ This scores the frequency of dyspeptic symptoms on a scale of $0-4$, intensity of dyspeptic symptoms on a scale of $0-2$, the frequency of use of over the counter medication on a scale of $0-2$, and frequency of prescribed medication on a score of $0-2$. Table 1 shows details of the scoring methods. The nature of the dyspepsia was assessed by determining the predominant symptom experienced by the patient. This involved the doctor interviewing the patients and asking them what they considered to be their most troublesome and frequent symptom. Only three doctors were involved in interviewing all the patients.

The validity of the abbreviated Dyspepsia Severity Score Questionnaire was assessed by comparing the dyspepsia score in 80 healthy volunteers, 80 patients with non-ulcer dyspepsia (NUD), and 70 patients with duodenal ulcer (DU). The mean score in these three groups was 1 (range 0-6), 6.7 (4-10), and 6.5 (3-10) respectively. The scores in the patients with NUD and DU were similar and both significantly higher than those in the healthy controls $(\mathrm{p}<0.001)$. 
Table 1 Modified Glasgow Dyspepsia Severity Score

\begin{tabular}{lc}
\hline & Score \\
\hline Frequency of dyspepsia & 0 \\
Never & 1 \\
1-2 Days/month & 2 \\
About 1 day/week & 3 \\
About 50\% of days & 4 \\
Most days & \\
Intensity of dyspepsia & 0 \\
Does not interfere with normal activities, i.e. & 1 \\
sleeping, socialising & 2 \\
Sometimes interferes with the above & \\
Usually interferes with the above & \\
Treatment required for dyspepsia & 0 \\
Over the counter preparations & 1 \\
$\quad$ None & 2 \\
$\quad$ Less than once/week & \\
$\quad$ More than once/week & 0 \\
Prescribed medication & 1 \\
$\quad$ None & 2 \\
$\quad$ Less than once/week & 10 \\
$\quad$ More than once/week & \\
Maximum aggregate score &
\end{tabular}

Table 2 Endoscopic findings

\begin{tabular}{ll}
\hline Endoscopic diagnosis & $\begin{array}{l}\text { No (\%) of patients } \\
(n=109)\end{array}$ \\
\hline $\begin{array}{l}\text { Duodenal ulcer only } \\
\text { Gastric ulcer only }\end{array}$ & $71(65)$ \\
$\begin{array}{l}\text { Both duodenal and gastric ulcer } \\
\text { Duodenal ulcer and oesophagitis }\end{array}$ & $12(11)$ \\
$\begin{array}{l}\text { Duodenal and gastric ulcer and } \\
\text { oesophagitis }\end{array}$ & $12^{\star}(11)$ \\
\hline
\end{tabular}

*Ten had grade I and two had grade II oesophagitis; †One had grade I and another had grade III oesophagitis

Within the two week period immediately following the assessment of the severity and nature of their dyspeptic symptoms the patients underwent a ${ }^{14} \mathrm{C}$ urea breath test ${ }^{2}$ and upper gastrointestinal endoscopy. At endoscopy biopsy specimens of the antral and body mucosa were taken for histological determination of $H$ pylori infection and rapid urease slide test (CLO test). ${ }^{3}$ Ulceration was diagnosed when there was an area of complete loss of mucosa of greater than $0.5 \mathrm{~cm}$ in diameter. Patients with erosive duodenitis were not included. Gastric ulcers were biopsied to exclude malignancy. Patients were classified as $H$ pylori positive if they had a positive ${ }^{14} \mathrm{C}$ urea

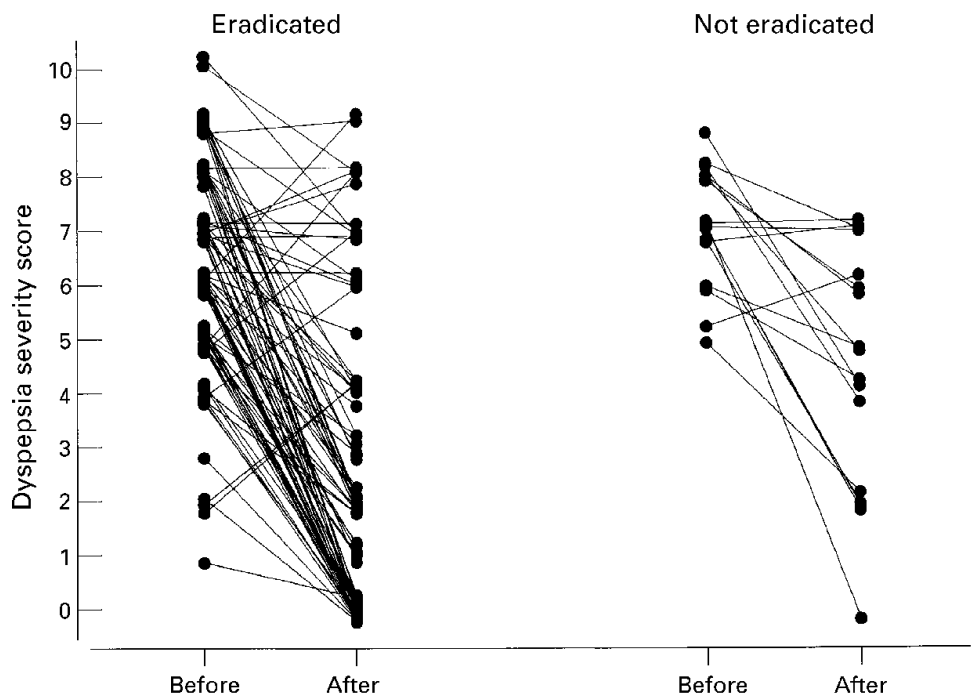

Figure 1 Individual dyspepsia scores in the ulcer patients before and after successful and unsuccessful $H$ pylori eradication therapy. breath test and CLO test and evidence of $H$ pylori like organisms on microscopy of mucosal biopsy specimens.

Patients who were confirmed to have endoscopic evidence of active ulcer disease associated with $H$ pylori infection were then prescribed a two week course of $H$ pylori eradication therapy. In the first 30 patients the eradication therapy consisted of two weeks of tripotassium dicitratobismuthate (De-Nol tab) $120 \mathrm{mg}$ three times daily plus metronidazole $400 \mathrm{mg}$ three times daily and amoxycillin 500 $\mathrm{mg}$ three times daily. In subsequent patients, omeprazole $20 \mathrm{mg}$ twice daily was used in place of tripotassium dicitratobismuthate. Patients with a history of allergy to penicillin received tetracycline $500 \mathrm{mg}$ three times daily in place of the amoxycillin. The patients then received an appointment to attend for a ${ }^{14} \mathrm{C}$ urea breath test six to eight weeks after completing the eradication therapy and an appointment to be reviewed at the clinic two to four weeks later. In the period between completing the eradication therapy and being reviewed three months later the patients were at liberty to take any medication they considered necessary to control persisting or recurrent symptoms.

On reassessment at the clinic, the severity of their dyspepsia over the preceding month was assessed by means of the Glasgow Dyspepsia Severity Score and this was performed with neither the patient nor the interviewer being aware of the result of the recent breath test and thus whether or not the infection had been eradicated.

\section{STATISTICAL ANALYSIS}

Differences in scores within individuals were quantified non-parametrically by calculating $95 \%$ confidence intervals (CI) based on the Wilcoxon test, for the population median change in score. The calculations were performed using Minitab statistical software.

\section{Results}

Of the 114 ulcer patients who were prescribed eradication therapy only five defaulted and were lost to follow up. The mean age of the 109 patients followed was 42 years (range 19-74) and 63 were men. The predominant symptoms on presentation in the 109 patients followed included epigastric pain/discomfort (64\%), retrosternal discomfort (17\%), reflux (7\%), generalised abdominal pain (5\%), nausea (3\%), right upper quadrant pain (3\%), and retching $(2 \%)$. Table 2 shows the endoscopic findings in these patients. At reassessment, 92 of the 109 had a negative ${ }^{14} \mathrm{C}$ urea breath test confirming eradication of the infection.

The median dyspepsia score at initial presentation in the $109 \mathrm{H}$ pylori positive ulcer patients who were followed up was 7 (range 1-10) (fig 1). At reassessment, following successful eradication of $H$ pylori, the median score was 2 (range 0-9) representing a median decrease following treatment of 4 (95\% CI 3.5 to 4.5). At reassessment following failure of eradication, the median score was 5 (range $0-7)$, a median decrease of 2 (95\% CI 1 to 4$)$. 
Table 3 Relation between resolution of symptoms (score <2) and eradication of $H$ pylori in the different patient groups

\begin{tabular}{|c|c|c|c|c|}
\hline & \multirow[b]{2}{*}{$\begin{array}{l}\text { All patients } \\
(n=109)\end{array}$} & \multicolumn{3}{|l|}{ Subgroup } \\
\hline & & $I(n=83)$ & $I I(n=95)$ & $I I I(n=73)$ \\
\hline $\begin{array}{l}\text { Proportion of patients in } \\
\text { whom } H \text { pylori was } \\
\text { eradicated whose symptoms } \\
\text { resolved (sensitivity) }\end{array}$ & 43/92 (47) & $37 / 74(50)$ & $41 / 81(51)$ & $35 / 66(53)$ \\
\hline $\begin{array}{l}\text { Proportion of patients with } \\
\text { persisting infection and } \\
\text { persisting symptoms } \\
\text { (specificity) }\end{array}$ & $16 / 17(94)$ & $8 / 9(89)$ & 13/14 (93) & 6/7 (86) \\
\hline $\begin{array}{l}\text { Predictive value of symptom } \\
\text { resolution for eradication of } \\
H \text { pylori } \\
\text { Predictive value of persistence } \\
\text { of symptoms for persisting } \\
\text { infection }\end{array}$ & $43 / 44(98)$ & $37 / 38(97)$ & $41 / 42(98)$ & $35 / 36(97)$ \\
\hline
\end{tabular}

Values are expressed as number (\%)

Subgroups: I, excluding patients with retrosternal discomfort or reflux as predominant symptoms; II, excluding patients with endoscopic oesophagitis; III, excluding patients with either or both of the above.

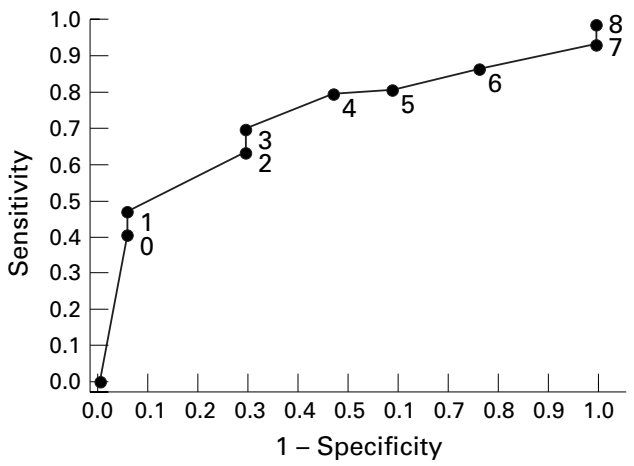

Figure 2 ROC curve for various post-treatment dyspepsia scores for predicting eradication of $\mathrm{H}$ pylori.

At reassessment, following successful eradication of the infection, $47 \%$ (43 of 92 patients) had complete or almost complete resolution of dyspepsia (score 0 or 1 ); $53 \%$ continued to experience dyspepsia with a median dyspepsia severity score of 4 (range 2-9). At reassessment following failed anti- $H$ pylori therapy only $6 \%$ ( 1 of 17) of patients had complete or almost complete resolution of dyspepsia (score 0 or 1 ).

Resolution of symptoms was a powerful predictor of eradication of $H$ pylori: $98 \%$ (43 of 44) of patients who had dyspepsia scores of less than 2 following anti- $H$ pylori therapy were eradicated of the infection. However, persistence of dyspeptic symptoms was a weak predictor of failure of eradication as only $25 \%$ (16 of 65 ) of those with persisting symptoms (score 2 or more) were still $H$ pylori positive (table 3).

Further analysis was undertaken to determine whether the high prevalence of persisting dyspepsia following eradication of $H$ pylori might be partly related to coexisting gastrooesophageal reflux disease. In the 66 patients without endoscopic evidence of oesophagitis or retrosternal discomfort and/or reflux as predominant symptoms at initial presentation, eradication of $H$ pylori produced resolution of dyspepsia in $53 \%$. In the 11 patients with endoscopic evidence of coexisting oesophagitis at initial presentation only $18 \%$ experienced resolution of dyspepsia following eradication of
H pylori and the corresponding figure for the 18 patients with retrosternal discomfort or reflux symptoms at initial presentation was 33\%. Ulcer patients with symptoms or signs indicating coexisting reflux disease thus had a lower frequency of symptomatic resolution following eradication of $H$ pylori.

We assessed whether excluding patients with retrosternal discomfort or reflux as predominant presenting symptoms would increase the value of persisting symptoms in predicting persisting infection. However, after exclusion of such patients the predictive value of persisting symptoms for persisting infection was $18 \%$ compared with $25 \%$ for all patients. The sensitivity and specificity of persisting symptoms for persisting infection was also unchanged after excluding the patients with retrosternal discomfort or reflux as their predominant presenting symptom (table 3 ). Likewise, after excluding the 14 patients with endoscopic evidence of coexisting oesophagitis the predictive value of persisting symptoms for persisting infection was not altered, being $25 \%$.

We investigated the possibility that a dyspepsia score other than less than 2 might be more accurate as a surrogate marker of posttreatment $H$ pylori status. This was assessed by constructing a receiver operated characteristic (ROC) curve in which the specificity is plotted against (1-sensitivity) for the full range of post-treatment dyspepsia scores (fig 2). This confirmed that a cut off point of a dyspepsia score of less than 2 was the most discriminating level.

\section{Discussion}

Dyspeptic symptoms are more difficult to measure than objective abnormalities such as endoscopic evidence of ulceration. The accurate assessment of the severity of dyspepsia requires the use of a validated method and for that reason we used the Glasgow Dyspepsia Severity Score. ${ }^{1}$ This has been shown to be a valid, responsive, and reproducible means of assessing the severity of dyspepsia in patients with ulcer disease and non-ulcer dyspepsia. It was originally assessed for determining dyspeptic symptoms over a six month period. In the present study, a slightly abbreviated version was used to allow us to measure symptoms over a one month period. Its validity when used over this shorter period was confirmed. Due to the subjective nature of dyspeptic symptoms, it is also essential that both the patient and interviewer are unaware of other measures of outcome of treatment. In the present study, neither the interviewer nor the patient was aware of the outcome of the anti- $H$ pylori therapy when evaluating the symptomatic response. It is also essential that the great majority of patients are reassessed following treatment as those who drop out may be unrepresentative and distort the result. A follow up rate of $96 \%$ was achieved in this study.

The Glasgow Dyspepsia Severity Score used to assess the severity of the dyspepsia was designed to provide a global score for all symptoms thought to be related to the upper 
Table 4 Influence of $H$ pylori eradication rate on resolution of symptoms (score <2) as a predictor of $H$ pylori eradication

\begin{tabular}{lll}
\hline Eradication rate (\%) & $\begin{array}{l}\text { Predictive value of symptom } \\
\text { resolution for eradication of } H \\
\text { pylori (\%) }\end{array}$ & $\begin{array}{l}\text { Predictive value of symptom } \\
\text { persistence for persisting infection } \\
(\%)\end{array}$ \\
\hline 60 & 92 & 54 \\
65 & 94 & 49 \\
70 & 95 & 43 \\
75 & 96 & 37 \\
80 & 97 & 31 \\
85 & 98 & 24 \\
90 & 99 & 16 \\
95 & 99 & 8 \\
\hline
\end{tabular}

gastrointestinal tract rather than to provide a score for individual symptoms, for example, epigastric pain, fullness, nausea, heartburn, and reflux. The reason for this is that patients with dyspepsia usually have several individual symptoms. ${ }^{45}$ In addition, the character of dyspepsia is unstable with $50 \%$ of patients reporting a change in their symptom profile within one year. ${ }^{5}$ This makes it impractical to score the severity of each individual symptom over time. In addition, scoring the severity of each individual dyspeptic symptom produces problems in statistical analysis in having to adjust significance of any change for the effects of multiple analyses. Consequently, we assessed the severity of dyspepsia by determining the global severity of all symptoms thought to be related to the upper gastrointestinal tract. In this study we also recorded the individual's predominant symptom incase which was useful in predicting symptomatic response. However, we are very aware of the limited value of dyspeptic symptoms, whether classified as symptom clusters or predominant symptoms, as indicators of the nature of any underlying pathology. ${ }^{6-8}$

At two to three months following eradication of $H$ pylori $47 \%$ of ulcer patients experienced complete or almost complete resolution of dyspepsia (score less than 2). The observation that a substantial proportion of the ulcer patients continued to experience dyspepsia following eradication of $H$ pylori is consistent with previous studies. ${ }^{910}$ The reason for persisting dyspepsia is unclear, but may be partly due to coexisting causes of dyspepsia such as reflux disease which are unrelieved by eradication of $H$ pylori. A recent study by Boyd has highlighted the fact that coexisting reflux disease is present in one third of duodenal ulcer patients. ${ }^{11}$ Coexisting reflux disease as a cause of persisting dyspepsia in some patients would be consistent with the fact that the resolution of dyspeptic symptoms was greater in our patients with no evidence of endoscopic oesophagitis or reflux type symptoms at presentation (53\%) than in those with either endoscopic oesophagitis $(18 \%)$ or reflux symptoms $(33 \%)$. It is possible that the symptomatic benefit from $H$ pylori eradication will increase with time as studies have shown that it takes six months for resolution of the functional abnormalities ${ }^{12}$ and may take longer for complete resolution of the morphological abnormalities ${ }^{13}$ caused by the infection.

This study indicates that resolution of dyspeptic symptoms following eradication therapy is a powerful predictor of successful eradication as 43 of 44 patients whose symptoms resolved had had the infection eradicated. The positive predictive value of resolution of symptoms as predictor of eradication of infection was thus $98 \%$. This finding is very similar to that of the only previous study to examine the value of dyspeptic symptoms in predicting post-anti- $H$ pylori status in ulcer patients. ${ }^{15}$ In that study Phull et al found resolution of dyspeptic symptoms to have a specificity for eradication of $H$ pylori infection of $87.5 \%$ at one month and of $97.5 \%$ at six months post-treatment. ${ }^{14}$

The predictive value of resolution of symptoms for eradication of $H$ pylori will be dependent on the actual eradication rate achieved. With the eradication rate of $84 \%$ obtained in our present study, resolution of dyspepsia predicted $H$ pylori eradication with $98 \%$ certainty. Over the eradication rate range of $60 \%$ to $95 \%$ the certainty with which resolution of dyspeptic symptoms would predict $H$ pylori eradication would range from $92 \%$ to $99 \%$ (table 4 ). The value of resolution of dyspepsia as predictor of eradication of the infection is therefore maintained over the full range of eradication rates likely to be encountered. These findings suggest that routine testing for eradication of $H$ pylori post-treatment is unnecessary in ulcer patients whose symptoms have fully resolved. However, patients with previously complicated ulcer disease should probably be retested routinely.

Our study also indicates that persistence of dyspeptic symptoms is a very weak predictor of persisting infection as only $25 \%$ of those with persisting symptoms were still infected. We attempted to see whether persisting dyspepsia would be a more reliable indicator of persisting infection if patients with endoscopic oesophagitis and/or symptomatic evidence of reflux disease at initial presentation were excluded. However, this did not increase the predictive value of persisting symptoms.

The value of persisting symptoms as predictor of persisting infection will also be affected by the eradication rate achieved. With our eradication rate of $84 \%$ persisting dyspepsia predicted failed eradication with $25 \%$ certainty. Over the eradication rate range of $60 \%$ to $95 \%$ the certainty of persisting dyspepsia predicting failed eradication would range from $54 \%$ to $8 \%$ (table 4 ). Thus, persisting dyspepsia is a weak to very weak predictor of persisting infection over the full range of eradication rates. For this reason it is important that patients with persisting dyspepsia following eradication therapy have their $H$ pylori status checked before prescribing a further course of anti- $H$ pylori therapy which is very likely to be inappropriate.

When assessing resolution of symptoms as an indicator of $H$ pylori status following eradication therapy, we selected a dyspepsia score of less than 2 as representing symptom resolution. This was based on validation studies with the dyspepsia severity score which indicated that this was the best value for discriminating between dyspepsia patients and healthy $H$ 
pylori negative volunteers. We analysed our data from the present study by means of an ROC curve to determine whether any other cut off point might be more suitable when measuring symptom response as an indicator of eradication of $H$ pylori. This confirmed that the value of less than 2 was indeed the most discriminating in this situation.

In summary, resolution of dyspepsia is a powerful predictor of eradication of $H$ pylori infection in ulcer patients whereas persistence of symptoms is a very weak predictor of persisting infection. This holds true over the full range of eradication rates likely to be encountered in clinical practice. In view of these findings we would conclude that it is unnecessary to confirm eradication of the infection routinely in patients with uncomplicated ulcer disease whose symptoms resolve following anti- $H$ pylori therapy. We also conclude that ulcer patients with persisting symptoms following anti- $H$ pylori therapy should have their $H$ pylori status routinely rechecked rather than be prescribed empirically a further course of anti- $H$ pylori therapy which is most likely to be inappropriate.

The authors wish to acknowledge the invaluable assistance of Mrs Dorothy Ronney in typing the manuscript and of the staff of the Department of Nuclear Medicine for performing the ${ }^{14} \mathrm{C}$ of the Department of Nuclear Medicine for performing the ${ }^{14} \mathrm{C}$
urea breath tests. This study was partially supported by a grant urea breath tests. This study was partially supported by a grant
from the Medical Research Council. The work was presented at from the Medical Research Council. The work was presented at the British Society of Gastroenterology meeting in Manchester
in September 1996 and published as an abstract in Gut (1996;39(suppl1):A34).
1 El-Omar E, Banerjee S, Wirz A, et al. The Glasgow Dyspepsia Severity Score-a tool for the global assessment of dys-
pepsia. Eur $\mathcal{F}$ Gastroenterol Hepatol 1996;8:967-71.

2 Neithercut WD, Milne A, Chittajallu RS, et al. Detection of Helicobacter pylori infection of the gastric mucosa by measurement of gastric aspirate ammonium and urea concentrations. Gut 1991;32:973-6.

3 Marshall BJ, Warren R, Francis GJ, et al. Rapid urease test in the management of Campylobacter pyloridis-associated gastritis. Am $\mathcal{F}$ Gastroenterol 1987;82:200-10.

4 Talley NJ, Weaver AL, Tesmer DL, et al. Lack of discriminant value of dyspeptic subgroups in patients referred for upper endoscopy. Gastroenterology 1993;105: referred for

5 Agreus L, Svardsudd K, Nyren O, et al. Irritable bowel syndrome and dyspepsia in the general population: overlap and lack of stabiliy over time. Gastroenterology 1995;109: $671-80$

6 Johnsen R, Bernersen B, Straume B, et al. Prevalences of endoscopic and histological findings in subjects with and without dyspepsia. $B M \mathcal{F}$ 1991;302:749-52.

7 Klauser AG, Schindlbeck NE, Muller-Lissner SA. Symptoms in gastro-oesophageal reflux disease. Lancet 1990; 335:205-8.

8 Johannessen $\mathrm{T}$, Petersen $\mathrm{H}$, Kleveland PM, et al. The predictive value of history of dyspepsia. Scand 7 Gastroenterol 1990;25:689-97.

9 Vakil N, McSorley D, Hahin B, et al. Recurrent symptoms after Helicobacter pylori treatment, endoscopic and microiological findings [abstract]. Gastroenterology 1997;112: A319.

10 Reilly TG, Ayres RCS, Poxon V, et al. Helicobacter pylori eradication in a clinical setting: success rates and the effect on the quality of life in peptic ulcer. Aliment Pharmacol Ther 1995;9:483-90.

11 Boyd EJS. The prevalence of oesophagitis in patients with duodenal ulcer or ulcer-like dyspepsia. Am f Gastroenterol 1996;91:1539-43

12 El-Omar E, Penman ID, Ardill JES, et al. Helicobacter pylori infection and abnormalities of acid secretion in patients with duodenal ulcer disease Gastroenterology 1995;109:681-91.

13 Solcia E, Villani L, Fiocca R, et al. Effects of eradication of Helicobacter pylori on gastritis in duodenal ulcer patients. Helicobacter pylori on gastritis in duodenal ulcer

14 Phull PS, Halliday D, Price AB, et al. Absence of dyspeptic symptoms as a test for Helicobacter pylori eradication. symptoms as a test for
$B M \mathcal{F} 1996 ; 312: 349-50$. 